\title{
Estragole blocks neuronal excitability by direct inhibition of $\mathrm{Na}^{+}$channels
}

\author{
K.S. Silva-Alves ${ }^{1}$, F.W. Ferreira-da-Silva ${ }^{1}$, D. Peixoto-Neves ${ }^{1}$, K.V. Viana-Cardoso ${ }^{2}$ \\ L. Moreira-Júnior ${ }^{1}$, M.B. Oquendo ${ }^{1}$, K. Oliveira-Abreu ${ }^{1}$, A.A.C. Albuquerque ${ }^{1}$, \\ A.N. Coelho-de-Souza ${ }^{1}$ and J.H. Leal-Cardoso ${ }^{1}$ \\ ${ }^{1}$ Laboratório de Eletrofisiologia, Instituto Superior de Ciências Biomédicas, Universidade Estadual do Ceará, Fortaleza, CE, Brasil \\ ${ }^{2}$ Curso de Fisioterapia, Faculdade de Medicina, Universidade Federal do Ceará, Fortaleza, CE, Brasil
}

\begin{abstract}
Estragole is a volatile terpenoid, which occurs naturally as a constituent of the essential oils of many plants. It has several pharmacological and biological activities. The objective of the present study was to investigate the mechanism of action of estragole on neuronal excitability. Intact and dissociated dorsal root ganglion neurons of rats were used to record action potential and $\mathrm{Na}^{+}$currents with intracellular and patch-clamp techniques, respectively. Estragole blocked the generation of action potentials in cells with or without inflexions on their descendant (repolarization) phase ( $\mathrm{N}_{\text {inf }}$ and $\mathrm{N}_{0}$ neurons, respectively) in a concentration-dependent manner. The resting potentials and input resistances of $\mathrm{N}_{\text {inf }}$ and $\mathrm{N}_{0}$ cells were not altered by estragole $(2,4$, and $6 \mathrm{mM})$. Estragole also inhibited total $\mathrm{Na}^{+}$current and tetrodotoxin-resistant $\mathrm{Na}^{+}$current in a concentration-dependent manner $\left(\mathrm{IC}_{50}\right.$ of 3.2 and $3.6 \mathrm{mM}$, respectively). Kinetic analysis of $\mathrm{Na}^{+}$current in the presence of $4 \mathrm{mM}$ estragole showed a statistically significant reduction of fast and slow inactivation time constants, indicating an acceleration of the inactivation process. These data demonstrate that estragole blocks neuronal excitability by direct inhibition of $\mathrm{Na}^{+}$channel conductance activation. This action of estragole is likely to be relevant to the understanding of the mechanisms of several pharmacological effects of this substance.
\end{abstract}

Key words: Estragole; Local anesthetic; Essential oil; Dorsal root ganglia; Phenylpropanoid; $\mathrm{Na}^{+}$current

\section{Introduction}

Estragole is a constituent of essential oils of many plants such as Ravensara anisata, Ocimum basilicum, and Croton zehntneri. These plants are widely used in folk medicine and popular cooking $(1,2)$. Their essential oils are extensively employed in aromatherapy (3). Estragole is also used as a flavoring agent in pharmaceutical, cosmetic, and food industries $(4,5)$ and as an antimicrobial for food preservation (6).

Estragole has many biological effects, including antioxidant and antimicrobial activities $(7,8)$. Its pharmacological activities are reported to be anxiolytic (9), to induce contraction of skeletal muscle (10), and to relax ileal and other vascular smooth muscles $(11,12)$. In addition to these activities, estragole has been shown to have an anti-inflammatory activity (13), which is pharmacologically potent (3-30 mg/kg per os) and is effective at oral doses smaller than those considered toxic $\left(L_{50}\right.$ values of 1200 and $1800 \mathrm{mg} / \mathrm{kg}$ for rats and $1250 \mathrm{mg} / \mathrm{kg}$ for mice) (14). In this connection it is interesting that its analogues, anethole and eugenol, block the effects of tumor necrosis factor- $\alpha$, which is a well-known proinflammatory cytokine (15).

Using an extracellular recording technique, we demonstrated that estragole blocks the excitability of rat sciatic nerve (16). However, the mechanism underlying this effect is unknown, and understanding how estragole affects excitable membranes may explain the mechanism of action of other pharmacological activities induced by this essential oil constituent.

Estragole is a phenylpropanoid, and some substances of this class are local anesthetics: they block excitability predominantly through direct inhibitory effects on $\mathrm{Na}^{+}$ channel conductance activation (17-20). For this reason, we hypothesized that estragole blocks excitability through a local anesthetic-like activity. To test this hypothesis we examined action potential (AP) generation and inward $\mathrm{Na}^{+}$currents in intact and isolated neurons derived from dorsal root ganglia (DRG). Our results revealed that 
estragole blocks the generation of AP in DRG neurons by a direct inhibition of voltage-gated activation of $\mathrm{Na}^{+}$ channel conductance. Thus, estragole appears to possess potent local anesthetic activity.

\section{Material and Methods}

\section{Animals, tissue dissection, and cell preparation}

Wistar rats (250-350 g) of both sexes were used throughout the study. They were maintained at constant temperature $\left(22 \pm 2^{\circ} \mathrm{C}\right)$ with a $12: 12$-h light-dark cycle and free access to food and water. All animals were cared for in compliance with the Guide for the Care and Use of Laboratory Animals, published by the United States National Institutes of Health (NIH Publication 27-89, revised 1996). All procedures were approved by the animal Ethics Committee of Universidade Estadual do Ceará (CEUA-UECE process \#06379067-0).

After rats were killed by $\mathrm{CO}_{2}$ inhalation, DRG were dissected and immediately placed in an ice-cold modified Locke's solution. For intracellular recordings, intact tissues were used on the same day of dissection. For patch-clamp recording, dissociated DRG neurons were prepared as described previously (21). Briefly, DRG were placed in $\mathrm{Ca}^{2+}$ - and $\mathrm{Mg}^{2+}$-free Hanks' balanced salt solutions, then placed in a dissociation solution, which consisted of $1.0 \mathrm{mg} / \mathrm{mL}$ collagenase type I, for $75 \mathrm{~min}$ and in $2.5 \mathrm{mg} / \mathrm{mL}$ trypsin for $15 \mathrm{~min}$, both in Hanks' balanced salt solutions at $37^{\circ} \mathrm{C}$. After they were incubated in the dissociation solutions, the cells were freed from the tissue by gently titrating the DRG using a fire-polished Pasteur pipette and transferred to Dulbecco's modified Eagle's medium containing $10 \%$ fetal bovine serum, $100 \mathrm{U} / \mathrm{mL}$ streptomycin, and $0.1 \mathrm{mg} / \mathrm{mL}$ penicillin, and then plated onto coverslips coated with $0.01 \%$ poly-Dlysine. The neurons were incubated in a $5 \% \mathrm{CO}_{2}$ atmosphere at $37^{\circ} \mathrm{C}$ and used within 6-48 h. All electrophysiological experiments were performed at room temperature $\left(\sim 22^{\circ} \mathrm{C}\right)$.

\section{Solutions and drugs}

The composition of modified Locke's solution was: $140 \mathrm{mM} \mathrm{NaCl}, 5.6 \mathrm{mM} \mathrm{KCl}, 1.2 \mathrm{mM} \mathrm{MgCl}, 2.2 \mathrm{mM}$ $\mathrm{CaCl}_{2}, 10 \mathrm{mM}$ glucose, and $10 \mathrm{mM}$ Tris-(hydroxymethylaminomethane). Hanks' balanced salt solution used in the dissociation protocol had the following composition:

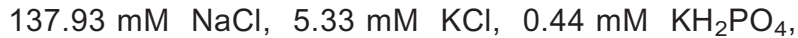
$4.0 \mathrm{mM} \mathrm{NaHCO} 3,0.3 \mathrm{mM} \mathrm{Na}_{2} \mathrm{HPO}_{4}$, and $5.6 \mathrm{mM}$ glucose. For patch-clamp recording, the composition of the bath solution was: $140 \mathrm{mM} \mathrm{NaCl}, 5.0 \mathrm{mM} \mathrm{KCl}, 1.8 \mathrm{mM}$ $\mathrm{CaCl}_{2}, 0.5 \mathrm{mM} \mathrm{MgCl} 2,5.0 \mathrm{mM}$ HEPES, and $5.0 \mathrm{mM}$ glucose. To study the $\mathrm{Na}^{+}$current in dissociated DRG neurons we used an external solution with the following composition: $40 \mathrm{mM} \mathrm{NaCl}, 70 \mathrm{mM}$ choline chloride, $3.0 \mathrm{mM} \mathrm{KCl}, 1.0 \mathrm{mM} \mathrm{CaCl}_{2}, 1.0 \mathrm{mM} \mathrm{MgCl}, 20 \mathrm{mM}$ tetraethylammonium chloride, $0.1 \mathrm{mM} \mathrm{CdCl}, 10 \mathrm{mM}$
HEPES, and $10 \mathrm{mM}$ glucose. The $\mathrm{pH}$ of all solutions was adjusted to 7.4 with $\mathrm{HCl}$, except for the modified external solution, which was adjusted with tetraethylammonium hydroxide. The internal solution contained $10 \mathrm{mM} \mathrm{NaCl}, 100 \mathrm{mM} \mathrm{CsCl}, 10 \mathrm{mM}$ HEPES, $11 \mathrm{mM}$ ethylene glycol tetraacetic acid, $10 \mathrm{mM}$ tetraethylammonium chloride, and $5.0 \mathrm{mM} \mathrm{MgCl}_{2}$, and the $\mathrm{pH}$ was adjusted to 7.2 with $\mathrm{CsOH}$. In some patch-clamp experiments, we added $300 \mathrm{nM}$ tetrodotoxin (TTX) to the modified external solution in order to block the TTXsensitive (TTX-S) component of the $\mathrm{Na}^{+}$current. The $\mathrm{Na}^{+}$current remaining in the presence of TTX was designated TTX-resistant (TTX-R). We used neurons of different sizes to investigate the effects of estragole on total and TTX-R Na ${ }^{+}$currents. To improve the quality of voltage clamp and data acquired, we chose to lower the extracellular $\mathrm{Na}^{+}$concentration in the external solution to reduce the electrochemical gradient and effectively decrease $\mathrm{Na}^{+}$current amplitudes. Thus, we used choline as a nonpermeate monovalent cation in partial substitution of external $\mathrm{Na}^{+} . \mathrm{Cs}^{+}$and tetraethylammonium were used to block $\mathrm{K}^{+}$channels, and $\mathrm{Cd}^{2+}$ was used to block $\mathrm{Ca}^{2+}$ channels.

Estragole was dissolved in dimethylsulfoxide (DMSO), and stock solutions were prepared daily. Stock solutions were added to the modified Locke's solution for intracellular recording and to modified external solutions for patch-clamp recording so as to provide a desired concentration of estragole with a final concentration of DMSO always lower than $0.2 \%(v / v)$. At this concentration DMSO did not alter any measurable electrophysiological parameters.

Estragole concentrations used for intracellular and patch-clamp recordings were 1-6 and 0.6-14 mM, respectively. All salts and drugs were purchased from Sigma Chemical (USA) or Reagen (Brazil) and were of analytical grade.

\section{Electrophysiological measurements and analysis}

Intracellular recordings. DRG were fixed to the floor of an acrylic chamber specially designed to permit superfusion with modified Locke's solution. The superfusion was maintained by a gravity flux and adjusted to $1.0-1.5 \mathrm{~mL} / \mathrm{min}$. The chamber was placed on a magnifying glass (model College Stereo, MLW Intermed, Germany), and the electrode movement and impalement were performed by a hydraulic micromanipulator (model MWO-3, Narishige International Inc., USA). Reservoirs containing control and drug solution were connected to the chamber by three-way valves that could rapidly switch between the main reservoir and test solutions. After impalement, cells were followed for 3-5 min to allow the stabilization of neuronal membrane properties. Neurons were exposed for up to $5 \mathrm{~min}$ to a given estragole concentration or until it blocked AP. Subsequently, a washout period began by switching to drug-free solutions. 
Intracellular recordings were made with thin-walled borosilicate glass microelectrodes $(1.0 \mathrm{~mm}$ OD, $0.5 \mathrm{~mm}$ ID, WPI Corp., USA) filled with a $3.0-\mathrm{M} \mathrm{KCl}$ solution. These microelectrodes were pulled with a micropipette puller (P-97 micropipette puller model, Sutter Instruments, USA) and had resistance ranging from 40 to $100 \mathrm{M} \Omega$. Pipettes were connected via an $\mathrm{Ag}-\mathrm{AgCl}$ wire to an Axoclamp-2B amplifier (Axon Instruments, USA).

Neurons were considered to be acceptable for study when they stabilized with resting potential $\left(E_{m}\right)$ more negative than $-50 \mathrm{mV}$ and with input resistance $\left(R_{\text {in }}\right)$ larger than $10 \mathrm{M} \Omega$ for 3-5 min after impalement. Voltage response and APs were elicited in response to depolarizing current pulses, which were $20-25 \%$ above the AP threshold. The recording was performed in bridge mode (bandwidth filter at $30 \mathrm{kHz}$ ) and in discontinuous (switched; $\sim 1.5 \mathrm{kHz}$ ) current injection mode. Headstage (unsampled) voltage was continuously monitored to ensure that it settled completely prior to sampling. Current and voltage outputs were sampled at $20 \mathrm{kHz}$, and data acquisition and storage were performed using computer acquisition hardware (Digidata 1200 model, Molecular Devices, USA).

The electrophysiological measurements were $E_{m}, R_{i n}$, and AP parameters: amplitude, duration, maximum rate of rise [ascendant, $\mathrm{dV} / \mathrm{dt}_{(\text {asc })}$ ], and maximum rate of fall of $\mathrm{AP}$ [descendant inclinations, $\mathrm{dV} / \mathrm{dt}_{(\mathrm{desc})}$, the absolute value of the minimum value of negative $d V / d t] . R_{\text {in }}$ was measured by means of Ohm's law (dividing the maximum voltage response due to hyperpolarizing current pulse) and AP amplitude by measuring the difference between maximum voltage amplitude in an $A P$ and $E_{m}$. AP duration was measured at $50 \%$ AP amplitude.

\section{Patch-clamp recordings}

Coverslips with dissociated DRG neurons were placed in a recording chamber on the stage of an inverted phasecontrast microscope (model Axiovert 200, Carl Zeiss Inc., USA) and perfused with bath solution. The perfusion system was composed of electronic valves (LFAA series, The Lee Co., USA) and a glass pipette located in the vicinity of the cell patch-clamped for recording the $\mathrm{Na}^{+}$ current.

The recording electrodes were pulled from thickwalled flint glass tubing with a micropipette puller (P-97 micropipette puller model, Sutter Instruments) and had a resistance range of 1.5-3.0 $\mathrm{M} \Omega$. Seal resistances were larger than $1 \mathrm{G} \Omega$ and voltage-clamp recordings were made in whole-cell patch-clamp configuration using an Axopatch 200B amplifier (Axon Instruments) driven by a Clampex program (version 10.2).

The neurons were voltage-clamped at $-80 \mathrm{mV}$ for all experimental manipulations. A $100-\mathrm{ms}$ voltage step to $0 \mathrm{mV}, 0.2-\mathrm{Hz}$ interval, was employed to elicit $\mathrm{Na}^{+}$ currents. The experimental time points were: control, with external solution perfusion only ( $\sim 30 \mathrm{~s})$; drug exposure, with estragole-containing solution (120-150 s); and washout/recovery, back to test perfusion solution. Capacitance and leakage subtraction were performed using a $\mathrm{P} / 6$ subtraction protocol. Series resistance compensation (70$90 \%$ ) was routinely employed to reduce voltage error. The liquid junction potential was not corrected in this set of experiments. The current was sampled at $40 \mathrm{kHz}$ and low-pass filtered at $2 \mathrm{kHz}$, and data acquisition and storage were performed using computer acquisition hardware (Digidata 1440A model, Axon Instruments).

To assess current kinetics, we measured time-to-peak for activation and inactivation decay time constants. Timeto-peak was determined by the time elapsed from initiation of voltage pulse test to the peak of $\mathrm{Na}^{+}$current. Inactivation decay time constants were estimated by fitting the decay phase of current trace to a doubleexponential function, denoted here as slow and fast inactivation time constants.

\section{Statistical analysis}

Data are reported as means $\pm S E$ with $n$ indicating the number of experiments. The Student $t$-test was used for parametric data and the Mann-Whitney test for nonparametric data. The difference in percentage of neurons blocked by estragole in intracellular recordings was determined by a chi-square test. For all concentrationresponse curves, $\mathrm{IC}_{50}$ values (concentration that inhibited the effect to $50 \%$ of its maximal magnitude) were measured by Hill equation adjustment of data points. Data were considered to be significant when $\mathrm{P}<0.05$.

\section{Results}

The effects of estragole on DRG neurons were studied on a total of 100 cells using intracellular recordings. Two different shapes of AP were observed (Figure 1A). Some neurons exhibited an inflexion or shoulder on the falling of repolarization phase of AP and were classified as $N_{\text {inf }}$; others did not (Figure 1A, left traces) and were designated $\mathrm{N}_{0}(22,23)$. Previous studies demonstrated that the neurons here classified as $\mathrm{N}_{\text {inf }}$ generally correspond to nociceptors, while $\mathrm{N}_{0}$ were classified as non-nociceptors $(22,24,25)$. The classification of a neuron as $N_{\text {inf }}$ or $N_{0}$ was based on the first derivative of the AP (inset panel in Figure $1 \mathrm{~A}$ ). The $\mathrm{dV} / \mathrm{dt}$ of the neurons, after crossing a zero value corresponding to the peak of the AP, decreased to a minimum and then, for the $\mathrm{N}_{0}$ but not for the $\mathrm{N}_{\text {inf }}$, increased monotonically toward zero.

The number of $\mathrm{N}_{0}$ and $\mathrm{N}_{\text {inf }}$ cells was 56 and 44 , respectively. All passive and AP parameters differed significantly between these two types of neurons (Table 1), except for rheobase ( $P>0.05$, Mann-Whitney test) and for $\mathrm{E}_{\mathrm{m}}(\mathrm{P}>0.05$, Student $t$-test).

Estragole possesses an inhibitory effect on AP generation, as seen in Figure 1. It blocked the AP for both $\mathrm{N}_{0}$ and $\mathrm{N}_{\text {inf }}$ groups of DRG neurons within minutes 

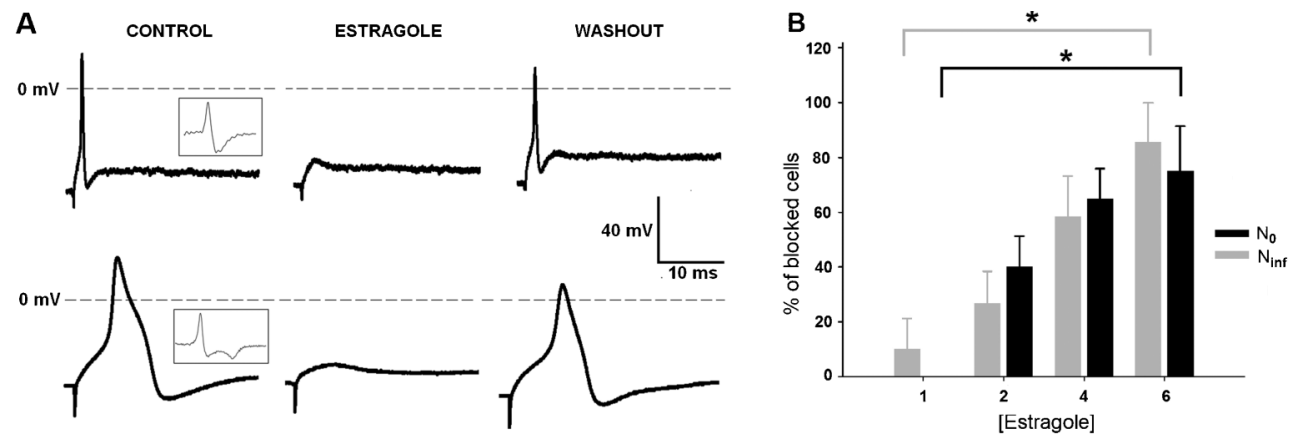

Figure 1. Effects of estragole on action potential recorded in $\mathrm{N}_{0}$ and $\mathrm{N}_{\text {inf }}$ cells. Tracings in pane/ $A$ show the effect of $4 \mathrm{mM}$ estragole on action potentials; insets show first derivative of voltage responses. Panel $B$ shows the percentage of neurons blocked by estragole (1.0$6.0 \mathrm{mM}$ ). The total number of cells was $8,20,20$, and 8 for $\mathrm{N}_{0}$, and $10,15,12$, and 7 cells for $\mathrm{N}_{\text {inf }}$, for each estragole concentration, respectively. Data are reported as means $\pm \mathrm{SE}$. ${ }^{*} \mathrm{P}<0.05$, chi-square test.

(up to 5 min at lower concentrations) and its effects were reversible after wash. Figure $1 \mathrm{~B}$ reports the percentage of $\mathrm{N}_{0}$ and $\mathrm{N}_{\text {inf }}$ neurons whose AP was blocked by estragole exposure, and the percentage of neurons was significantly blocked in a concentration-dependent manner $(\mathrm{P}<0.05$, chi-square test).

The $E_{m}$ and $R_{\text {in }}$ values in $N_{0}$ and $N_{\text {inf }}$ neurons that underwent complete blockade of AP generation were measured in different concentrations of estragole (2$6 \mathrm{mM}$; Figure 2). Over a variable concentration range, estragole (2-6 mM) did not alter the $E_{m}$ (Figure 2A) and $R_{\text {in }}$ (Figure 2B) of $N_{0}$ and $N_{\text {inf }}$ cells $(P>0.05$, Student $t$-test).

AP inhibition in the absence of measurable alterations of $E_{m}$ and $R_{i n}$ suggests that estragole may have a direct effect on $\mathrm{Na}^{+}$channel conductance activation. In order to further elucidate an effect on $\mathrm{Na}^{+}$channel function, DRG neurons were dissociated and $\mathrm{Na}^{+}$currents were recorded with patch-clamp techniques. To ensure that we were dealing with currents produced selectively by $\mathrm{Na}^{+}$, we performed pilot experiments where all $\mathrm{Na}^{+}$from

Table 1. Electrophysiological properties of $\mathrm{N}_{0}$ and $\mathrm{N}_{\text {inf }}$ cells in dorsal root ganglia.

\begin{tabular}{lcr}
\hline Parameters & $\mathrm{N}_{0}(\mathrm{n}=56)$ & $\mathrm{N}_{\text {inf }}(\mathrm{n}=44)$ \\
\hline Resting potential $(\mathrm{mV})$ & $-57.3 \pm 1.1$ & $-55.5 \pm 1.6$ \\
Input resistance $(\mathrm{M} \Omega)$ & $17.6 \pm 1.4$ & $54.7 \pm 10.5^{*}$ \\
Rheobase $(\mathrm{pA})$ & $1570.9 \pm 119.0$ & $1352.5 \pm 162.1$ \\
$\mathrm{dV} / \mathrm{dt}_{(\mathrm{asc})}(\mathrm{V} / \mathrm{s})$ & $183.4 \pm 9.5$ & $112.8 \pm 10.2^{*}$ \\
$\mathrm{dV} / \mathrm{dt}_{(\text {desc) }}(\mathrm{V} / \mathrm{s})$ & $116.4 \pm 6.3$ & $60.6 \pm 3.2^{*}$ \\
Amplitude $(\mathrm{mV})$ & $74.5 \pm 1.7$ & $83.6 \pm 2.0^{*}$ \\
Duration $(\mathrm{ms})$ & $1.0 \pm 0.1$ & $2.9 \pm 0.3^{*}$ \\
\hline
\end{tabular}

Data are reported as means $\pm \mathrm{SE}$ for cells with $\left(\mathrm{N}_{\text {inf }}\right)$ or without $\left(\mathrm{N}_{0}\right)$ inflexions. $\mathrm{dV} / \mathrm{dt}$ : maximum rate of rise or fall of action potential. ${ }^{*} \mathrm{P}<0.05$, Student $t$-test for amplitude and MannWhitney test for resistance, ascendant (asc) and descendant (desc) inclinations and action potential duration. the external solution was replaced by choline. Under these conditions no current was observed (data not shown).

Total $\mathrm{Na}^{+}$current (a mixture of TTX-S and TTX-R $\mathrm{Na}^{+}$currents) and TTX-R Na${ }^{+}$currents were recorded in isolated DRG neurons. The neuronal capacitances in cells with total $\mathrm{Na}^{+}$current and TTX-R current were $63.7 \pm 3.2$ $(n=40)$ and $44.5 \pm 4.7 \mathrm{pF}(n=24)$, respectively. The current kinetics was also different for the two types of $\mathrm{Na}^{+}$currents (Table 2).

Estragole inhibited total and TTX-R Na ${ }^{+}$currents in a voltage- and concentration-dependent manner (Figure $3 \mathrm{~A}$ ). These effects were partially reversible upon wash (Figure $3 \mathrm{~B}$ and $\mathrm{C}$ ). The time courses of $\mathrm{Na}^{+}$current inhibition developed within $150 \mathrm{~s}$ and were the same for both currents. The pharmacological potency was similar for total and TTX-R Na${ }^{+}$currents: $I_{50}$ values were $3.2 \pm 0.6$ and $3.6 \pm 1.1 \mathrm{mM}$, respectively.

Because calculated $\mathrm{IC}_{50}$ values were similar for both currents (3.2 and $3.6 \mathrm{mM}$ for total and TTX-R Na ${ }^{+}$ currents), we next analyzed the actions of $4 \mathrm{mM}$ estragole on kinetics parameters, time-to-peak, and inactivation time constants (Figure 4). There was a statistically significant reduction for the time-to-peak value of TTX- $\mathrm{R} \mathrm{Na}^{+}$current $(\mathrm{P}<0.05$, Student $t$-test), but no reduction was observed in total $\mathrm{Na}^{+}$current (Figure 4). Fast and slow inactivation time constants (Figure $4 \mathrm{~B}$ and $\mathrm{C}$ ) were reduced for both currents, indicating an acceleration of current inactivation in the presence of $4 \mathrm{mM}$ estragole. For the slow-time constant, there were significant differences in total and TTX-R Na ${ }^{+}$currents following $4 \mathrm{mM}$ estragole when compared with control $(\mathrm{P}<0.05$, Student $t$-test). For the fast-time constant, statistical significance was found only for total $\mathrm{Na}^{+}$current $(\mathrm{P}<0.05$, Student $t$-test $)$.

\section{Discussion}

The main finding of the present research is that estragole blocks AP detonation and causes inhibition of 

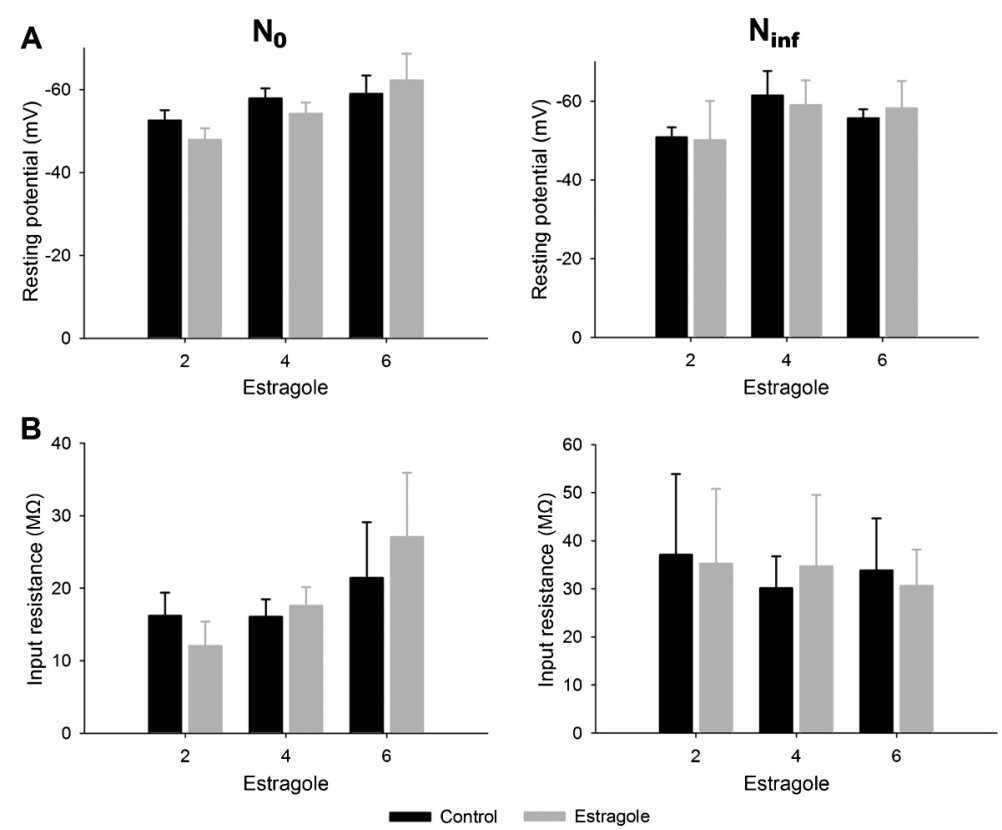

Figure 2. Effects of estragole on passive electrical properties of dorsal root ganglia neurons. Panels $A$ and $B$ report resting potential and input resistance, respectively, recorded in $\mathrm{N}_{0}$ and $\mathrm{N}_{\text {inf }}$ cells. At the estragole concentrations employed (2-6 mM), there were no significant differences between control and estragole treatment for either type of cells $(P>0.05$, Student $t-$ test). Data are reported as means $\pm S E$. The number of experiments was $n=6-12$ and $n=4-7$ for $\mathrm{N}_{0}$ and $\mathrm{N}_{\text {inf }}$, respectively.
$\mathrm{Na}^{+}$channel conductance activation in DRG neurons. Both these effects were observed at similar pharmacological concentrations, suggesting that the blockade of voltage-dependent $\mathrm{Na}^{+}$current underlies the inhibition of AP generation. Our current results confirm our hypothesis for the mechanism of action of estragole-induced blockade of neuronal excitability - namely, that this substance inhibits neuronal excitability by primary blockade of voltage-dependent activation of $\mathrm{Na}^{+}$channel conductance. This mechanism is a novel and relevant finding. These results may be important for an understanding of the pharmacological effects of estragole and of the widespread use of this substance in industry, and as a constituent of several essential oils in aromatherapy.

Besides the blockade of APs and $\mathrm{Na}^{+}$current, other aspects of estragole action on DRG neurons deserve consideration. At the concentrations that block AP and $\mathrm{Na}^{+}$currents, estragole produced no significant changes in $E_{m}$ and $R_{\text {in }}$ (passive electrophysiological properties).
Modifications in membrane $\mathrm{R}_{\text {in }}$ are frequently associated with changes in $E_{m}$. This is because many $\mathrm{K}^{+}$conductances are active at or near $E_{m}$ (26). On the other hand, changes in $\mathrm{Na}^{+}$conductance had little or no visible changes in $E_{m}$ or $R_{i n}$; these passive membrane properties are usually unaffected by alterations in $\mathrm{Na}^{+}$conductances (27). Thus, our data, while supporting the hypothesis that estragole inhibits excitability by blocking voltage-dependent $\mathrm{Na}^{+}$current, gave no indication that estragole acts on $\mathrm{K}^{+}$channels. The direct action of estragole on $\mathrm{Na}^{+}$channels indicates that this essential oil constituent possesses potent local anesthetic activity (28).

The dependence of excitability inhibition on $\mathrm{Na}^{+}$ current blockade and independence on changes in passive electrophysiological parameters shown by estragole were found for other terpenes and terpenoids like thymol (29), linalool (21), eugenol $(19,20)$, carvacrol (17), and menthol (30). This is not always the case, however,

Table 2. Kinetic parameters of total and TTX-R Na ${ }^{+}$current of dorsal root ganglion neurons.

\begin{tabular}{lcc}
\hline Parameters & $\begin{array}{c}\text { Total Na }{ }^{+} \text {current } \\
(\mathrm{n}=40)\end{array}$ & $\begin{array}{c}\text { TTX-R Na } \\
(\mathrm{N}=24)\end{array}$ \\
\hline Capacitance (pF) & $63.7 \pm 3.2$ & $44.5 \pm 4.7$ \\
Maximum peak current (pA) & $10178.7 \pm 959.5$ & $4516.0 \pm 811.5^{*}$ \\
Fast decay inactivation constant (Tau fast - ms) & $1.1 \pm 0.1$ & $2.4 \pm 0.2^{*}$ \\
Slow decay inactivation constant (Tau slow - ms) & $6.0 \pm 0.7$ & $10.2 \pm 1.0^{*}$ \\
Time-to-peak (ms) & $1.3 \pm 0.1$ & $2.4 \pm 0.1^{*}$ \\
\hline
\end{tabular}

Data are reported as means \pm SE. TTX-R: tetrodotoxin-resistant. ${ }^{*} \mathrm{P}<0.05$, Student $t$-test for fast decay inactivation constant and timeto-peak, and Mann-Whitney test for maximum peak current and slow decay inactivation constant. 


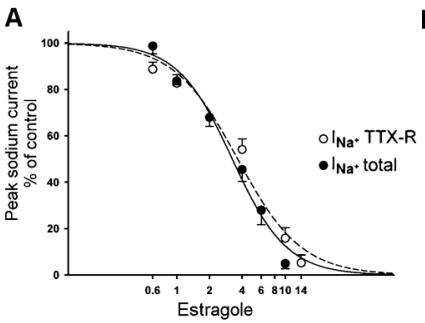

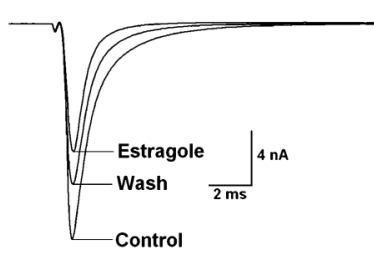

C

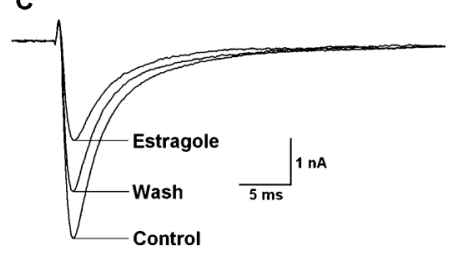

Figure 3. Estragole-induced inhibitory effect on total $\left(\mathrm{INa}^{+}\right.$total) and on tetrodotoxin-resistant $\left(\mathrm{INa}^{+} \mathrm{TTX}^{-\mathrm{R})} \mathrm{Na}^{+}\right.$current recorded in $\mathrm{N}_{0}$ and $\mathrm{N}_{\text {inf }}$ neurons. Panel A shows concentration-response curves $(0.6-14 \mathrm{mM})$ for the effect of estragole on total $\mathrm{Na}^{+}$current and on TTX-R Na ${ }^{+}$current. Panels $B$ and $C$ show representative traces of the effects of $4 \mathrm{mM}$ estragole on total (panel $B$ ) and TTX-R (panel C) $\mathrm{Na}^{+}$currents. There was partial recovery with washout. For $\mathrm{INa}^{+}$total, the number of experiments was $\mathrm{n}=4-12$ and for INa ${ }^{+}$TTX$R$, it was $n=4-5$ for each estragole concentration used.

as 1,8-cineole, a terpenoid, was demonstrated to cause depolarization of the resting membrane and to block excitability, mainly indirectly, via the effect of depolarization voltage-dependent $\mathrm{Na}^{+}$current activation (31).

Data from intracellular recordings suggested that the mechanism of action of estragole on excitability is that it has a direct effect on $\mathrm{Na}^{+}$channels. Two distinct $\mathrm{Na}^{+}$ currents can be characterized in different DRG neurons: TTX-S and TTX-R. These currents are observed in different populations of DRG neurons based on their soma diameters $(32,33)$. APs can be triggered solely by TTX-S, by TTX-R currents, or by a mixture of both (3335). According to the classification used in this study $\left(\mathrm{N}_{0}\right.$ and $\mathrm{N}_{\text {inf }}$ cells), we expected that $\mathrm{N}_{0}$ and $\mathrm{N}_{\text {inf }}$ cells would possess a mixture of TTX-S and TTX-R Na ${ }^{+}$currents, but that $\mathrm{N}_{\text {inf }}$ cells would have a predominance of TTX-R.

We observed that $\mathrm{N}_{\text {inf }}$ cells had much longer AP durations. This increased AP duration may be produced by an inward $\mathrm{Ca}^{2+}$ current that is activated during the AP depolarization. It is also a possible contributor to the inflection observed on the repolarization limb of the AP (35). However, it is worth mentioning that $\mathrm{Ca}^{2+}$ currents cannot promote an AP with the characteristics of $\mathrm{N}_{0}$ or $\mathrm{N}_{\text {inf }}$ here described. Our patch-clamp data showed that estragole blocked the amplitude of both currents (total and TTX-R) with similar $I_{50}$ values (3.2 and $3.6 \mathrm{mM}$ for
TTX-S and TTX-R, respectively; Figure 3), indicating similar pharmacological potency. This suggests that estragole has no preference for $\mathrm{Na}^{+}$current subtypes.

Besides estragole's effect on the amplitude of $\mathrm{Na}^{+}$ current, it also reduced kinetic parameters of $\mathrm{Na}^{+}$current (time-to-peak and inactivation time constants; Figure 4). At $4 \mathrm{mM}$ (approximately the $\mathrm{IC}_{50}$ for excitability and $\mathrm{Na}^{+}$ current blockade), estragole might have influenced neuron excitability via changes in $\mathrm{Na}^{+}$current kinetics. The kinetic parameters shown in Table 2 are similar to those in the literature for the $\mathrm{Na}^{+}$currents in DRG neurons (33). Also, the reduction in inactivation time constants promoted by estragole is in agreement with the effects of other terpenes and terpenoids like eugenol (20) and menthol (30).

Estragole possesses several biological and pharmacological activities. The present study adds an additional effect - namely, a local anesthetic effect. This new local anesthetic effect adds to the list of other pharmacological actions of estragole, such as antimicrobial (7), antioxidant (8), anti-edematogenic, and anti-inflammatory (13) effects, and places this substance as a candidate for therapeutic usefulness to treat ulcerations (infected or not), for example, and similar illnesses. In addition to these activities, one can consider that anethole, with a molecular structure very similar to estragole, has been
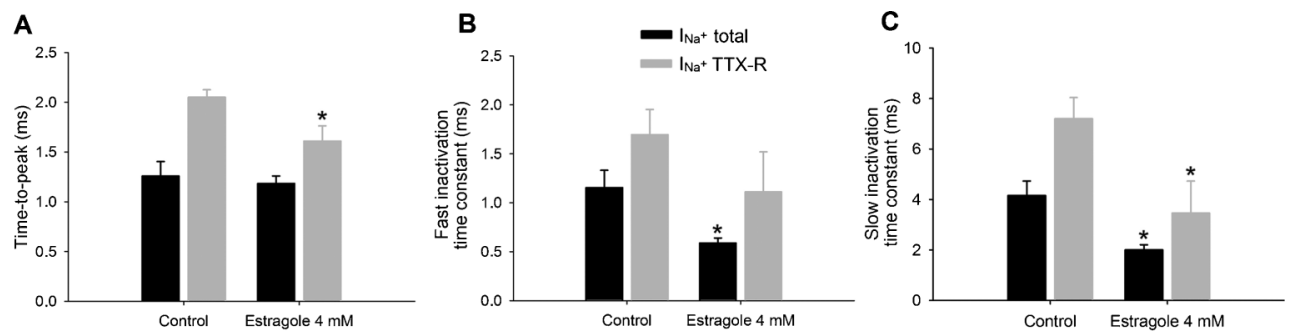

Figure 4. Effects of $4 \mathrm{mM}$ estragole on kinetic parameters of total $\left(\mathrm{INa}^{+}\right.$total) and tetrodotoxin-resistant $\left(\mathrm{INa}{ }^{+} \mathrm{TTX}_{-} \mathrm{R}\right) \mathrm{Na}^{+}$current. Panel $A$ shows time-to-peak parameter and panels $B$ and $C$ show fast and slow inactivation time constants. Data are reported as means \pm SE for $n=5-6$. ${ }^{*} P<0.05$, statistical difference of $4 \mathrm{mM}$ estragole effects on $\mathrm{INa}^{+}$total or INa ${ }^{+}$TTX-R compared to control (Student $t$-test). 
documented to have procicatrizing activity (36). This prospect also increases when one takes into consideration recent studies showing that long-lasting per os administration of $37.5 \mathrm{mg} / \mathrm{kg}$ estragole showed no toxic effects (37), suggesting that extracts having estragole as the principal constituent, like fennel seed extract, have anticancer (for certain types of cancer) and antioxidant activities, and radical scavenging potential (38).

It is noteworthy that the local anesthetic activities of estragole may help shed light on the actions of other essential oils that contain estragole. For example, the essential oil of Croton zehntneri contains estragole and is documented to have anti-nociceptive activity (39). It is known that part of the inflammatory mechanism is mediated through the nervous system, and a local anesthetic activity may contribute to the anti-inflammatory effect (40).

Previous studies of our group (16) investigated the effects of estragole on myelinated fibers of the sciatic nerve with conduction velocity between 40 and $100 \mathrm{~m} / \mathrm{s}$; myelinated fibers with lower conduction velocities and unmyelinated fibers were not recorded. The present investigation, using intracellular recordings, investigated the effect of estragole on $\mathrm{N}_{0}$ and $\mathrm{N}_{\text {inf }}$ neurons and demonstrated that estragole had similar pharmacological

\section{References}

1. Tisserand R, Balacs T. Essential oil safety: a guide for health care professionals. New York: Churchill Livingstone; 1995.

2. Leal-Cardoso JH, Fonteles MC. Pharmacological effects of essential oils of plants of the northeast of Brazil. An Acad Bras Cienc 1999; 71: 207-213.

3. Craveiro AA, Fernandes AG, Andrade CHS, Matos FJA, Alencar JW, Machado MIL. Óleos essenciais de plantas do Nordeste. Fortaleza: Edições UFC; 1981.

4. De Vincenzi M, Silano M, Maialetti F, Scazzocchio B. Constituents of aromatic plants: II. Estragole. Fitoterapia 2000; 71: 725-729, doi: 10.1016/S0367-326X(00)00153-2.

5. Masten S. Terpinolene. Review of toxicological literature. North Carolina: Research Triangle Park; 1999.

6. Lachowicz KJ, Jones GP, Briggs DR, Bienvenu FE, Wan J, Wilcock $A$, et al. The synergistic preservative effects of the essential oils of sweet basil (Ocimum basilicum L.) against acid-tolerant food microflora. Lett Appl Microbiol 1998; 26: 209-214, doi: 10.1046/j.1472-765X.1998.00321.x.

7. Friedman M, Henika PR, Mandrell RE. Bactericidal activities of plant essential oils and some of their isolated constituents against Campylobacter jejuni, Escherichia coli, Listeria monocytogenes, and Salmonella enterica. J Food Prot 2002; 65: 1545-1560.

8. Morais SM, Júnior FEAC, Silva ARA, Neto JSM, Rondina D, Leal-Cardoso $\mathrm{JH}$. Atividade antioxidante de óleos essenciais de espécies de Croton do Nordeste do Brasil. Quím Nova 2006; 29: 907-910, doi: 10.1590/S0100-40422006000500004.

9. Cosentino RM, Norte MC, Lazarini CA. Estragole-induced behavioural changes in rats. Phytother Res 2004; 18: 921-924, potency and efficacy in both types of cells. The similar actions of estragole on these two types of neurons indicate that this terpenoid affects a wide range of axon diameters. $\mathrm{N}_{\text {inf }}$ represents predominantly $A \delta$ afferents and C-neurons (slowly conducting fibers that are specified as nociceptors), while $N_{0}$ represents $A \alpha / \beta$ afferent neurons (intermediate conducting fibers associated with mechanoreceptors) $(22,24,25)$. Thus, estragole has no preference for any particular type of primary sensory afferent axon.

In conclusion, our data demonstrate that estragoleinduced blockade of the excitability in peripheral nerves is very probably due to a local anesthetic mechanism. Thus, estragole may be a potentially useful drug for therapeutic use.

\section{Acknowledgments}

The authors thank Mr. Pedro Militão de Albuquerque Neto for technical assistance and Dr. Daniel Weinreich for improving and correcting the manuscript. Research supported by CNPq, CAPES, Fundação Cearense de Apoio ao Desenvolvimento Cientifico e Tecnológico (FUNCAP), and Instituto Superior de Ciências Biomédicas, Universidade Estadual do Ceará (ISCBUECE).

doi: 10.1002/ptr.1583.

10. Albuquerque AA, Sorenson AL, Leal-Cardoso JH. Effects of essential oil of Croton zehntneri, and of anethole and estragole on skeletal muscles. J Ethnopharmacol 1995; 49: 41-49, doi: 10.1016/0378-8741(95)01301-6.

11. Coelho-de-Souza AN, Barata EL, Magalhães PJC, Lima CC, Leal-Cardoso $\mathrm{JH}$. Effects of the essential oil of Croton zehntneri, and its constituent estragole on intestinal smooth muscle. Phytother Res 1997; 11: 299-304, doi: 10.1002/ (SICI)1099-1573(199706)11:4<299::AID-PTR99>3.0.CO; 2-A.

12. Soares PM, Lima RF, de Freitas PA, Souza EP, Assreuy AM, Criddle DN. Effects of anethole and structural analogues on the contractility of rat isolated aorta: Involvement of voltage-dependent $\mathrm{Ca}^{2+}$-channels. Life Sci 2007; 81: 1085-1093, doi: 10.1016/j.lfs.2007.08.027.

13. Ponte EL, Sousa PL, Rocha MV, Soares PM, Coelho-deSouza AN, Leal-Cardoso JH, et al. Comparative study of the anti-edematogenic effects of anethole and estragole. Pharmacol Rep 2012; 64: 984-990.

14. Opdyke DL. Monographs on fragrance raw materials. Food Cosmet Toxicol 1976; 14: 601-633, doi: 10.1016/S00156264(76)80015-6.

15. Chainy GB, Manna SK, Chaturvedi MM, Aggarwal BB. Anethole blocks both early and late cellular responses transduced by tumor necrosis factor: effect on NF-kappaB, AP-1, JNK, MAPKK and apoptosis. Oncogene 2000; 19: 2943-2950, doi: 10.1038/sj.onc.1203614.

16. Leal-Cardoso JH, Matos-Brito BG, Lopes-Junior JE, VianaCardoso KV, Sampaio-Freitas AB, Brasil RO, et al. Effects 
of estragole on the compound action potential of the rat sciatic nerve. Braz J Med Biol Res 2004; 37: 1193-1198, doi: 10.1590/S0100-879X2004000800009.

17. Joca HC, Cruz-Mendes $\mathrm{Y}$, Oliveira-Abreu K, Maia-Joca RP, Barbosa R, Lemos TL, et al. Carvacrol decreases neuronal excitability by inhibition of voltage-gated sodium channels. $J$ Nat Prod 2012; 75: 1511-1517, doi: 10.1021/np300050g.

18. Ravens U, Wettwer E, Hala O. Pharmacological modulation of ion channels and transporters. Cell Calcium 2004; 35: 575-582, doi: 10.1016/j.ceca.2004.01.011.

19. Moreira-Lobo DC, Linhares-Siqueira ED, Cruz GM, Cruz JS, Carvalho-de-Souza JL, Lahlou S, et al. Eugenol modifies the excitability of rat sciatic nerve and superior cervical ganglion neurons. Neurosci Lett 2010; 472: 220224, doi: 10.1016/j.neulet.2010.02.009.

20. Cho JS, Kim TH, Lim JM, Song JH. Effects of eugenol on $\mathrm{Na}^{+}$currents in rat dorsal root ganglion neurons. Brain Res 2008; 1243: 53-62, doi: 10.1016/j.brainres.2008.09.030.

21. Leal-Cardoso JH, da Silva-Alves KS, Ferreira-da-Silva FW, dos Santos-Nascimento T, Joca HC, de Macedo FH, et al. Linalool blocks excitability in peripheral nerves and voltagedependent $\mathrm{Na}^{+}$current in dissociated dorsal root ganglia neurons. Eur J Pharmacol 2010; 645: 86-93, doi: 10.1016/ j.ejphar.2010.07.014.

22. Harper AA, Lawson SN. Electrical properties of rat dorsal root ganglion neurones with different peripheral nerve conduction velocities. J Physiol 1985; 359: 47-63.

23. Amir R, Devor M. Chemically mediated cross-excitation in rat dorsal root ganglia. J Neurosci 1996; 16: 4733-4741.

24. Harper AA, Lawson SN. Conduction velocity is related to morphological cell type in rat dorsal root ganglion neurons. $J$ Physiol 1985; 359: 31-46.

25. Villiere $\mathrm{V}$, McLachlan EM. Electrophysiological properties of neurons in intact rat dorsal root ganglia classified by conduction velocity and action potential duration. $J$ Neurophysiol 1996; 76: 1924-1941.

26. Gutman GA, Chandy KG, Grissmer S, Lazdunski M, McKinnon D, Pardo LA, et al. International Union of Pharmacology. LIII. Nomenclature and molecular relationships of voltage-gated potassium channels. Pharmacol Rev 2005; 57: 473-508, doi: 10.1124/pr.57.4.10.

27. Catterall WA, Goldin AL, Waxman SG. International Union of Pharmacology. XLVII. Nomenclature and structurefunction relationships of voltage-gated sodium channels. Pharmacol Rev 2005; 57: 397-409, doi: 10.1124/pr.57.4.4.

28. Altman RS, Smith-Coggins R, Ampel LL. Local anesthetics. Ann Emerg Med 1985; 14: 1209-1217, doi: 10.1016/S01960644(85)81031-3.
29. Haeseler G, Maue D, Grosskreutz J, Bufler J, Nentwig B, Piepenbrock $S$, et al. Voltage-dependent block of neuronal and skeletal muscle sodium channels by thymol and menthol. Eur J Anaesthesiol 2002; 19: 571-579.

30. Gaudioso C, Hao J, Martin-Eauclaire MF, Gabriac M, Delmas P. Menthol pain relief through cumulative inactivation of voltage-gated sodium channels. Pain 2012; 153: 473484, doi: 10.1016/j.pain.2011.11.014.

31. Ferreira-da-Silva FW, Barbosa R, Moreira-Junior L, dos Santos-Nascimento T, de Oliveira-Martins MD, Coelho-deSouza AN, et al. Effects of 1,8-cineole on electrophysiological parameters of neurons of the rat superior cervical ganglion. Clin Exp Pharmacol Physiol 2009; 36: 1068-1073, doi: 10.1111/j.1440-1681.2009.05188.x.

32. Ogata N, Tatebayashi $\mathrm{H}$. Ontogenic development of the TTX-sensitive and TTX-insensitive $\mathrm{Na}^{+}$channels in neurons of the rat dorsal root ganglia. Brain Res Dev Brain Res 1992; 65: 93-100, doi: 10.1016/0165-3806(92)90012-L.

33. Elliott AA, Elliott JR. Characterization of TTX-sensitive and TTX-resistant sodium currents in small cells from adult rat dorsal root ganglia. J Physiol 1993; 463: 39-56.

34. Scholz A, Vogel W. Tetrodotoxin-resistant action potentials in dorsal root ganglion neurons are blocked by local anesthetics. Pain 2000; 89: 47-52, doi: 10.1016/S03043959(00)00345-6.

35. Renganathan M, Cummins TR, Waxman SG. Contribution of $\mathrm{Na}(\mathrm{v}) 1.8$ sodium channels to action potential electrogenesis in DRG neurons. J Neurophysiol 2001; 86: 629-640.

36. Cavalcanti JM, Leal-Cardoso JH, Diniz LR, Portella VG, Costa CO, Linard CF, et al. The essential oil of Croton zehntneri and trans-anethole improves cutaneous wound healing. J Ethnopharmacol 2012; 144: 240-247, doi: 10.1016/j.jep.2012.08.030.

37. Bristol DW. NTP 3-month toxicity studies of estragole (CAS No. $140-67-0$ ) administered by gavage to $\mathrm{F} 344 / \mathrm{N}$ rats and B6C3F1 mice. Toxic Rep Ser 2011; 82: 1-111.

38. Mohamad RH, El-Bastawesy AM, Abdel-Monem MG, Noor AM, Al-Mehdar HA, Sharawy SM, et al. Antioxidant and anticarcinogenic effects of methanolic extract and volatile oil of fennel seeds (Foeniculum vulgare). J Med Food 2011; 14: 986-1001, doi: 10.1089/jmf.2008.0255.

39. Oliveira AC, Leal-Cardoso JH, Santos CF, Morais SM, Coelho-de-Souza AN. Antinociceptive effects of the essential oil of Croton zehntneri in mice. Braz $J$ Med Biol Res 2001; 34: 1471-1474.

40. Murakami M, Hirano T. The molecular mechanisms of chronic inflammation development. Front Immunol 2012; 3: 323, doi: 10.3389/fimmu.2012.00323. 